\title{
Influences of Solar Incident Angle on Power Generation Efficiency of PV Modules under Field Conditions
}

\author{
Kazuhiro Soga ${ }^{* 1}$ and Hiroshi Akasaka ${ }^{2}$ \\ ${ }^{1}$ Associate Professor, Dept. of Architecture, Faculty of Engineering, Kagoshima University, Japan \\ ${ }^{2}$ Professor, Dept. of Architecture, Faculty of Engineering, Kagoshima University, Japan
}

\begin{abstract}
In this report, we examined influences of solar incident angle on the power generation efficiency of photovoltaic (PV) modules based on a measurement, during winter, at Kagoshima in Japan $\left(31.570^{\circ} \mathrm{N}, 130.545^{\circ} \mathrm{E}\right)$. It was indicated that the power generation efficiency of PV modules deteriorates with time depending on the solar incident angle, and that there are cases where the power generation efficiency sharply drops if the incident angle exceeds $60^{\circ}$ and the reflectance of cover glass exceeds 0.2 . Such drop of power generation efficiency dependent on incident angle clearly appears at clear time when the proportion of direct components of solar radiation increases. Furthermore, it was pointed out that the average value of power generating efficiency during winter including all weather conditions produces differences of $10 \%$ or so, depending on the difference of average value during the period of incident angle.
\end{abstract}

Keywords: PV module, incident angle, reflection loss, module temperature

\section{Introduction}

Variation of the power generation efficiency of polycrystal Si PV module under field condition is dependent on various factors, e.g.,module temperature, incident angle of sunlight as well as spectral distribution of solar irradiation. Therefore, it is necessary to clarify the effect of these factors on the power generation efficiency in order to accurately predict realistic electric power generation of $\mathrm{PV}$ module installed in buildings.

E.A.Sjerps-Koomen et al. ${ }^{1)}$ developed a simple model for calculating PV module reflection losses depending on solar incident angle under field conditions. The model calculations in U.K., Netherlands, Italy and Zimbabwe showed that the reflection losses relative to standard condition (STC) are depend on geographical latitude of the location. Furthermore, E.A.Sjerps-Koomen et al. showed that tilt, orientation and seasonal dependence are significant.

On the other hand, there are small reports on measurements or calculations of the PV module reflection losses under the field conditions in Japan. In this article, we examined the effect of solar incident angle on power generation efficiency of polycrystal Si PV module with a measurement, during winter, at Kagoshima in Japan.

\footnotetext{
*Contact Author: Kazuhiro Soga, Associate Professor,
}

Dept. of Architecture, Faculty of Engineering, Kagoshima University 1-21-40 Korimoto, Kagoshima-city, Kagoshima 890-0065 Japan Tel: +81(0)99-285-8306 Fax: +81(0)99-285-8301

e-mail: soga@aae.kagoshima-u.ac.jp

(Received May 7, 2003 ; accepted September 10, 2003 )

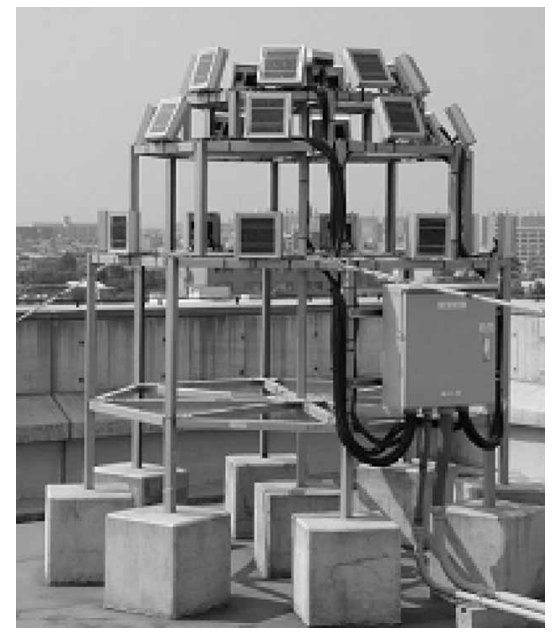

Fig.1. PV Modules Installed for Measurement

\section{Methods \\ Measuring system}

The PV modules forming the subject of measurement are the total number of 25 modules installed in 8 directions (N, NE, E, SE, S, SW, W, NW) x 3 tilt angles $\left(30,60,80^{\circ}\right)$ and in horizontal plane. Table 1 shows the specification of the PV modules. Those modules are installed on the roof of a 7-storied building in the site of Kagoshima University. The output (current-voltage) of the $25 \mathrm{PVs}$ is being measured at 2-minute intervals by using I-V curve tracer, by switching from one to another through a Cell selector. Moreover, module temperature, global irradiance, direct irradiance and diffuse irradiance 
are measured at 1-minute intervals. The details of other measured items and measuring instruments are indicated on Table 2. PV modules in the directions of south $80^{\circ}$, southwest $60^{\circ}$ and west $30^{\circ}$ were excluded from the object of observation in this report, because of their large difference in rated output from other modules.

Table 1. Specifications of PV Module

\begin{tabular}{llc}
\hline Item & Specification & Average \\
\hline Solar cell & polycrystal silicon & - \\
Dimension of cover glass & $200 \times 200 \times 3.2(\mathrm{~mm})$ & \\
Dimension of module & $200 \times 200 \times 36(\mathrm{~mm})$ & - \\
Dimension of cell & $150 \times 155.5 \times 0.4(\mathrm{~mm})$ & - \\
Open circuit voltage & $0.591 \sim 0.609 \mathrm{~V}$ & $0.598 \mathrm{~V}$ \\
Short circuit current & $7.44 \sim 7.58 \mathrm{~A}$ & $7.51 \mathrm{~A}$ \\
Max-output power & $2.51 \sim 3.03 \mathrm{~W}$ & $2.92 \mathrm{~W}$ \\
Max-output power voltage & $0.377 \sim 0.45 \mathrm{~V}$ & $0.428 \mathrm{~V}$ \\
Max-output power current & $6.6 \sim 7.0 \mathrm{~A}$ & $6.83 \mathrm{~A}$ \\
\hline
\end{tabular}

\section{Calculation of power generating efficiency}

As power generating efficiency of PV modules, we used the system performance ratio ${ }^{2)} K$ defined by formula (1). $K$ expresses the proportion of actual amount of power generation $E_{P}$ against ideal amount of power generation.

$$
K=\frac{E_{P}}{P_{A S} \cdot \frac{I_{T G}}{I_{T G S}}}
$$

Where

$E_{p}$ :maximum output power at field condition[W]

$P_{A S}$ :maximum output power at standard test condition (STC) [W]

$I_{T G}$ :solar irradiation on a module plane $\left[\mathrm{kW} / \mathrm{m}^{2}\right]$

$I_{T G S}$ :solar irradiation on a module plane at STC $\left(=1 \mathrm{~kW} / \mathrm{m}^{2}\right)$

The maximum output power $E_{P}$ was calculated by using formula (2).

$E_{P}=I_{\max } \cdot V_{\max }$
Where

$I_{\max }$ : maximum output power current of PV cell [A]

$V_{\max }^{\max }:$ maximum output voltage of PV cell [V]

$I_{\max }$ and $V_{\text {max }}$ are values measured by using the I-V curve tracer at field condition. Therefore, influences of conversion loss by inverter are not included in $E_{P}$. The tilted surface irradiance $I_{T G}$ was calculated from the measurements of direct and diffuse irradiance by using the anisotropic sky irradiance model of Perez ${ }^{3}$. In the calculation of tilted surface irradiance, the albedo was supposed to be $10 \%$. The value of albedo around the measurement site is in the range of approximately 5 to $20 \%$.

The system performance ratio $K$ varies under the influences of shadings, module temperature and solar incident angle. Therefore, $K$ was expressed as a function of several loss factors in formula (3).

$$
K=K_{H} \cdot K_{P T} \cdot K_{P}
$$

Where

$K_{H}$ : shading loss factor

$K_{P T}$ : temperature loss factor

$K_{P}:$ reflection loss factor

$K_{P T}$ is defined as well-known formula (4).

$K_{P T}=1+\alpha\left(T_{C}-T_{S}\right)$

Where

$\alpha$ : temperature coefficiente $\left[{ }^{\circ} \mathrm{C}^{-1}\right]$

$T_{C}$ : module temperature at field condition $\left[{ }^{\circ} \mathrm{C}\right]$

$T_{S}$ : module temperature at $\mathrm{STC}\left(=25^{\circ} \mathrm{C}\right)$

To clarify the influence of solar incident angle on power generation efficiency, $K_{P}$ was calculated by using formula (5). In the calculation of $K_{P}, K_{H}$ was set at 1.0 based on surroundings in the measurement site.

$$
K_{P}=K / K_{P T}
$$

Temperature correction of power generating efficiency A temperature coefficient $\alpha$ is required for calculating

\begin{tabular}{|c|c|c|c|}
\hline Measuring item & Unit & Interval & Instrument \\
\hline Global irradiance & $\mathrm{kW} / \mathrm{m}^{2}$ & $1 \mathrm{~min}$. & Pyranometer (EKO MS-802), thermopile, ISO Secondary standard \\
\hline Direct irradiance & $\mathrm{kW} / \mathrm{m}^{2}$ & $1 \mathrm{~min}$. & Pyrhel iometer (EKO MS-53A), half angle: $2.5^{\circ}$ \\
\hline Diffuse irradiance & $\mathrm{kW} / \mathrm{m}^{2}$ & $1 \mathrm{~min}$ & Pyranometer (EKO MS-802) + Shading ball (half angle: $2.5^{\circ}$ ) \\
\hline Sunshine duration & minutes & $3 \mathrm{~min}$. & Sunshine duration meter (EKO MS-093), threshold value : $120 \mathrm{~W} / \mathrm{m}^{2}$ \\
\hline Spectral irradiance & $\mathrm{kW} / \mathrm{m}^{2}$ & $10 \mathrm{~min}$. & Spectroradiometer (EKO MS-700), wavelength range:350 to $1050 \mathrm{~nm}$, resolution: $10 \mathrm{~nm}$ \\
\hline Sky radiance distribution & $\mathrm{W} / \mathrm{m}^{2} \cdot \mathrm{sr}$ & $10 \mathrm{~min}$. & Sky Scanner (EKO MS-301LR), scanning points: 145 , half angle of radiance sensor:5. $5^{\circ}$ \\
\hline Sky luminance distribution & $\mathrm{kcd} / \mathrm{m}^{2}$ & $10 \mathrm{~min}$. & Sky Scanner (EKO MS-301LR), scanning points: 145 , half angle of luminance sensor:5.5 \\
\hline Albedo & $\%$ & $1 \mathrm{~min}$. & Albedo meter (EKO MS-22) \\
\hline Air temperature & ${ }^{\circ} \mathrm{C}$ & $1 \mathrm{~min}$. & Thermister + Radiation shields (naturally ventilated) \\
\hline Relative humidity & $\%$ & $1 \mathrm{~min}$. & Thin polymer film type sensor + Radiation shields (naturally ventilated) \\
\hline Module temperature & ${ }^{\circ} \mathrm{C}$ & $1 \mathrm{~min}$. & CC thermocouple, installed on the back of the PV module \\
\hline Module output current & A & $2 \mathrm{~min}$. & I-V curve tracer (EKO MP-123B10)+Cell selector (EKO MI-505-12) \\
\hline Module output voltage & $\mathrm{V}$ & $2 \mathrm{~min}$. & I-V curve tracer (EKO MP-123B10)+Cell selector (EKO MI-505-12) \\
\hline Module out power & W & $2 \mathrm{~min}$. & calculated from the current and vol tage measured by I-V curve tracer \\
\hline
\end{tabular}
$K_{P T}$. In this report, $\alpha$ was determined with a regression

Table 2. Measured Items and Instruments 
analysis from the relationship between $K$ and module temperature obtained by actual measurement. At that time, no proper value of $\alpha$ can be determined if any factor other than module temperature is contained in the power generating efficiency $K$. Therefore, to eliminate influences of incident angle dependency, etc. in the analysis, we eliminated data having an incident angle over $60^{\circ}$. Fig. 2 shows the relationship between $K$ and module temperature on a clear day. From the chart, we can see that $K$ is dependent on module temperature and that the power generating efficiency drops as the temperature goes up. The amount of change in $K$ against module temperature determined from the regression line in the chart was $-0.0056\left[{ }^{\circ} \mathrm{C}^{-}\right.$ ${ }^{1}$ ]. $K_{P}$ was calculated from formula (4) and formula (5) by using this temperature coefficient $\alpha$. Fig. 3 shows the relationship between module temperature and $K_{p}$. Hardly any change dependent on module temperature appears in $K_{P}$, although there is some slight dispersion. This is an effect of temperature correction. Therefore, we determined temperature correction by the same method and calculated $K_{p}$ also for other PV modules.

A study will be made on the influences of solar incident angle on power generating efficiency of PV, with the use of the power generating efficiency $K_{P}$ submitted to temperature correction. Incident angle as mentioned here refers to the angle formed by the normal line and the sunlight on the surface of the module. In the observations hereafter, we used measured values at 2minute intervals. Data with an altitude of the sun no higher than $5^{\circ}$ was excluded from the analysis to avoid influences of obstacles on the ground surface.

\section{Results \\ Deterioration of power generating efficiency}

Fig. 4 indicates deterioration with time of $K_{P}$ in northeast, east, southeast, south and northwest directions and in horizontal plane on February 3, 2002 which was a clear day. In horizontal plane, the power generating efficiency fares about at values close to the rating during the daytime, although it is slightly lower in the time zones after dawn and before sunset. In the south direction, the power generating efficiency tends to become approximately 5\% lower than the rating during the daytime, although it generally shows changes of efficiency similar to those in horizontal plane. We studied relationship between this trend and the temperature correction, but could not clarify the cause of this change.

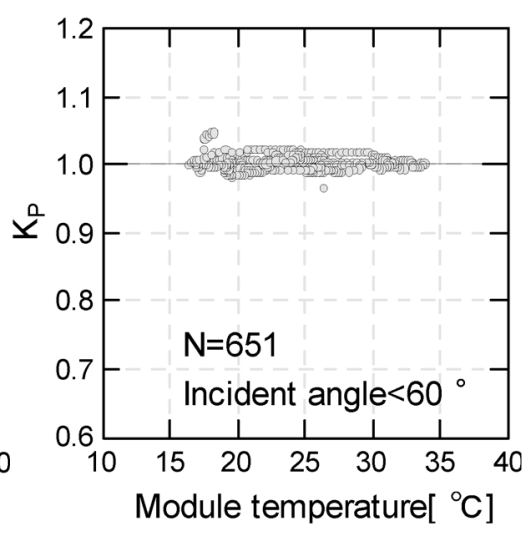

Fig.3. Module Temperature versus $K_{P}$
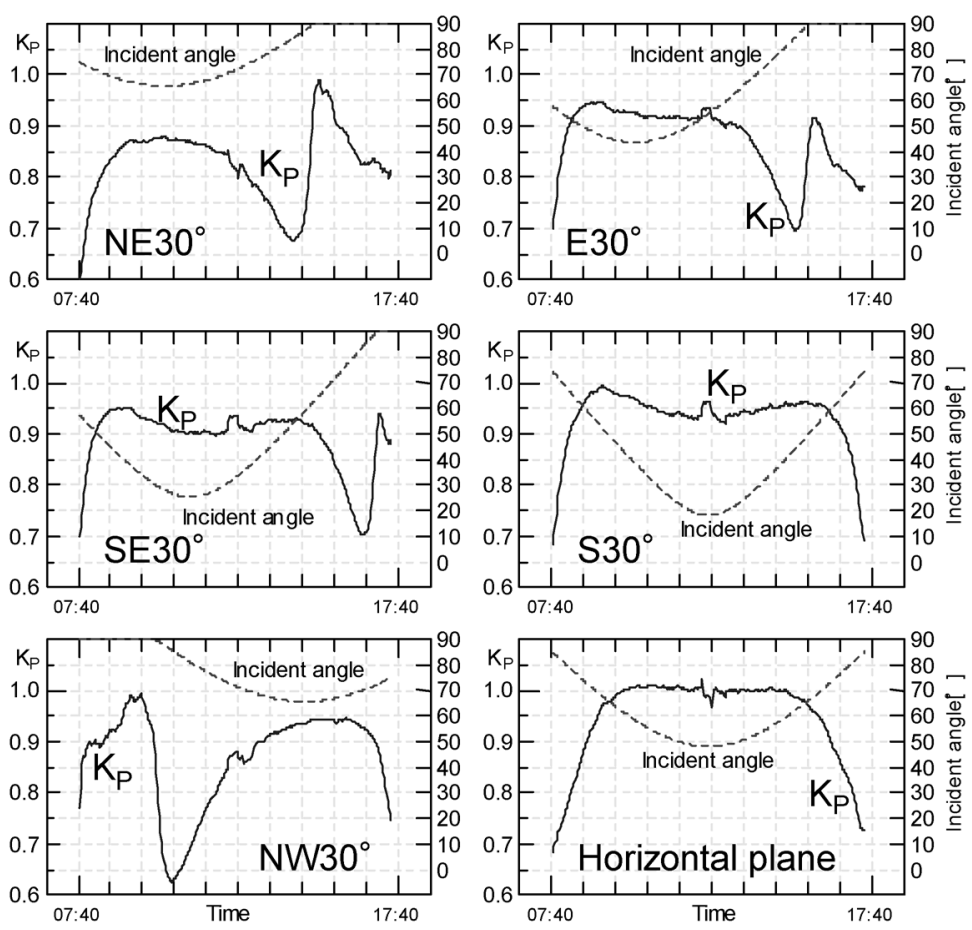

Fig.4. Deterioration with Time of $K_{P}$

For those horizontal plane and south direction, no conspicuous change of efficiency was seen, except at hours after dawn and before sunset. On the other hand, in the modules in the directions of northeast, east and southeast, $K_{P}$ drops to around 0.7 in the afternoon in all of those directions. Furthermore, there was also an example in which $K_{P}$ drops to 0.63 in the morning as in the northwest direction, showing a trend different from that in horizontal plane and south direction.

\section{Relationship between power generating efficiency and incident angle}

Now let us observe such differences in power generating efficiency in relation to the incident angle of sunlight. On the module in southeast direction which showed a sharp drop of efficiency in the afternoon, the efficiency dropped in the time zone in which the incident angle changes from $60^{\circ}$ to $90^{\circ}$. Similarly, as we checked 
the relationship between evolution of power generating efficiency and incident angle on other modules, the time zone in which a large drop of power generating efficiency was a range where the incident angle is approximately over $60^{\circ}$ without exception. On a module in which the incident angle remains over $60^{\circ}$ throughout the day like that in northeast direction, the power generating efficiency generally remains low. On the contrary, in horizontal plane and south direction, the incident angle is lower than $60^{\circ}$ all day long, and no drop of power generating efficiency as on other modules is observed. These observations made on a clear day indicate that the power generating efficiency deteriorates with time depending on the incident angle of the sunlight.

Fig. 5 is a relational chart of power generating efficiency and incident angle. From the chart, we can see that the power generating efficiency shows a trend of sharply dropping when the incident angle is larger than $60^{\circ}$. On the other hand, Fig. 6 shows calculated values of the transmittance $(\tau)$, absorptance (a) and reflectance $(\rho)$ of the cover glass as a function of incident angle. We can see that the reflectance of cover glass of PV module increases when the incident angle is larger than $60^{\circ}$. Furthermore, Fig. 7 illustrates relation between power generating efficiency and reflectance $(\rho)$ of cover glass. The power generating efficiency varies in inverse proportion to reflectance $(\rho)$ when $\rho$ is larger than 0.2 .

Such drop of power generating efficiency dependent on the incident angle is believed to be produced, in the course in which the sunlight reaches the PV cell, as part of the sunlight is reflected on the surface of the cover glass and the amount of sunlight contributing to power generation decreases.

\section{Incident angle dependency of power generating efficiency on clear and cloudy days}

The drop of power generating efficiency dependent on the incident angle may vary, in the degree of influences, depending on the weather or on the amount of direct irradiance entering through the surface of the module. For that reason, we checked changes in power generating efficiency by incident angle dependency, by using as indicator the proportion of the direct components against the total irradiance entering on the surface of the module (direct tilted surface irradiance/ tilted surface irradiance).

Here, changes by incident angle of $K_{P}$ were compared between a case in which the proportion of direct components against the total irradiance on tilted surface is larger than $60 \%$ (clear day) and a case in which that proportion is no higher than 5\% (cloudy day). These direct components do not include any highly directional circumsolar irradiance component from the sky around

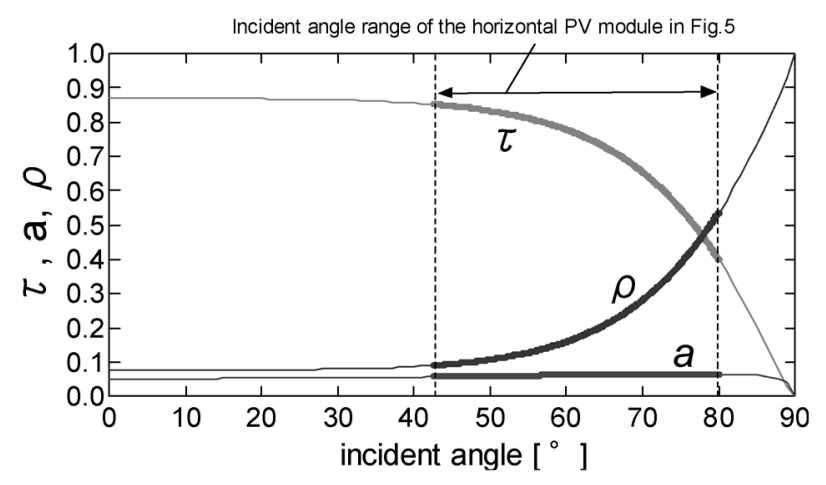

Fig.6. $\tau, \mathrm{a}, \rho$ as a Function of Incident Angle

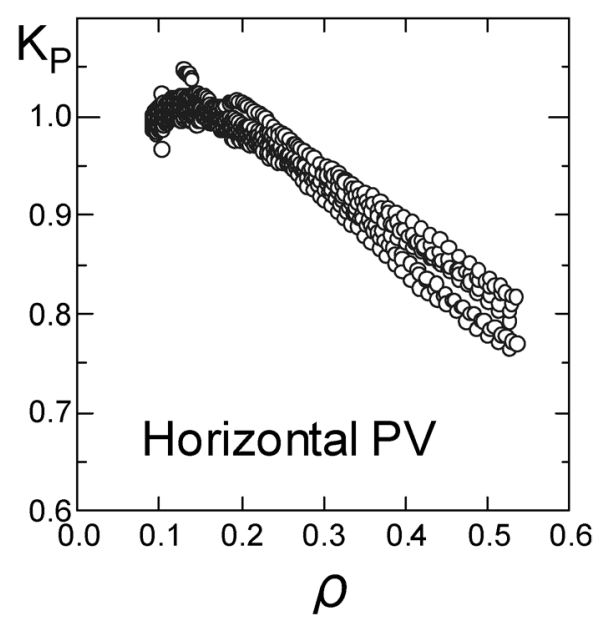

Fig.7. Reflectance versus $K_{P}$

the sun. Firstly, Fig. 8 indicates the results on cloudy days. $K_{P}$ in the chart shows the average values by incident angles. Moreover, the averaged period is the period from January 1 to February 28, 2002. At cloudy time when the proportion of direct components is no more than $5 \%$, the efficiency slightly drops in the range of incident angle 


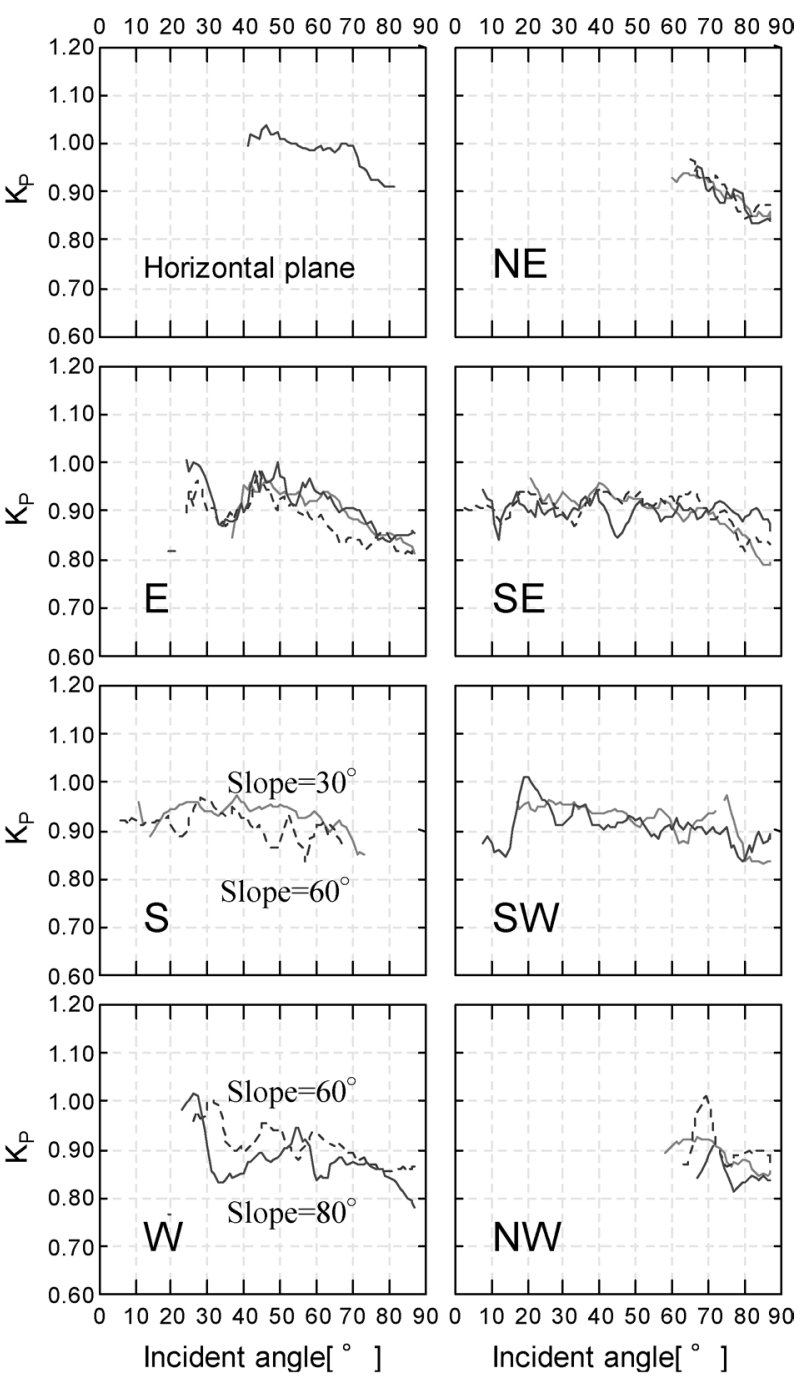

Fig.8. Incident Angle versus Averaged $K_{P}$ on Cloudy Days

of $70^{\circ}$ or over with the modules in horizontal plane, northeast and east directions, though this judgment is rather difficult to make because of large dispersion of data. However, in other directions or at other incident angles, hardly any change of efficiency dependent on incident angle is observed. On the other hand, at clear time when the proportion of direct components exceeds $60 \%$, the trend of dependence on incident angle of efficiency appears more clearly compared with cloudy time. From this fact, we can see that the change of power generating efficiency dependent on incident angle is affected by the weather (proportion of direct components). Also from Fig. 9, a trend of drop of efficiency can be seen, in the range in which the incident angle exceeds $50 \sim 60^{\circ}$, in the same way as in Fig. 5. Furthermore, to compare the drop of power generating efficiency by directions, at incident angles over $60^{\circ}$, the drop of power generating efficiency is more conspicuous with the modules in northeast, northwest, east and southeast directions. Especially with the module in the northeast direction, there is a large difference between the value at clear time and the value at cloudy time.

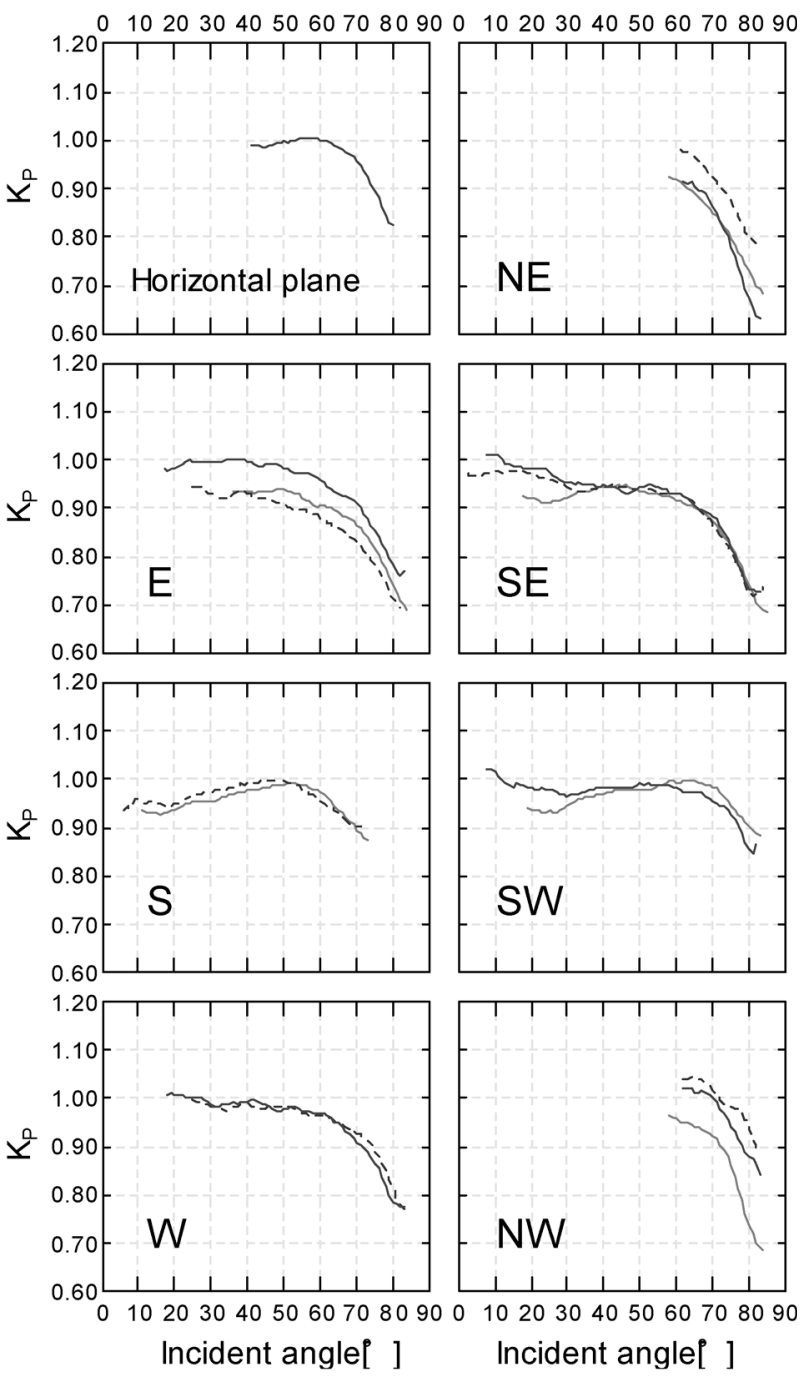

Fig.9. Incident Angle versus Averaged $K_{P}$ on Clear Days

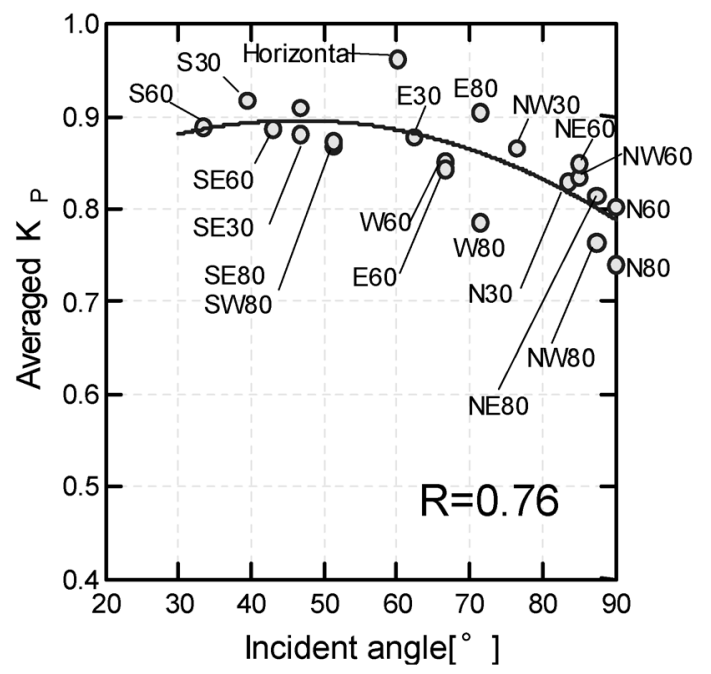

Fig. 10. Averaged Incident Angle versus $K_{P}$ for All Weather Conditions (January 1 to February 28, 2002.) 


\section{Averaged relation between power generating efficiency and incident angle}

On each module, we calculated the average value of $K_{P}$ during the measuring period, and checked the relation between power generating efficiency and incident angle for all weather conditions. Fig. 10 indicates the relation between average $K_{P}$ during the period and incident angle. In this chart, although modules with large dispersions are also seen in horizontal plane, east $80^{\circ}$, west $80^{\circ}$, etc., there is certainly a correlation between the average power generating efficiency during the period and incident angle, and the coefficient of correlation turned out to be 0.76. According to the regression curve in Fig. 10, we can see that the power generating efficiency of modules having an average value during the period of incident angle of $80^{\circ}$ or over is about $10 \%$ lower compared with modules having a value of $50^{\circ}$ or under. This chart clearly shows differences of power generating efficiency by incident angles (differences due to conditions of direction and slope angle of the modules). The dispersion of data observed in horizontal plane, east $80^{\circ}$ and west $80^{\circ}$ must form the subject of further study in the future.

\section{Conclusions}

In this report, we examined influences of solar incident angle on the power generating efficiency of PV modules during winter.

1) It was indicated that the power generating efficiency of PV modules deteriorates with time depending on the solar incident angle, and that there are cases where the power generating efficiency sharply drops if the incident angle exceeds $60^{\circ}$ and the reflectance of cover glass exceeds 0.2 .
2) It was shown that, such drop of power generating efficiency dependent on incident angle clearly appears at clear time when the proportion of direct components of solar radiation increases.

3) It was pointed out that the average value of power generating efficiency during winter including all weather conditions produces differences of $10 \%$ or so, depending on the difference of average value during the period of incident angle.

\section{Acknowledgments}

This study was conducted as a joint study by Kyushu Electric Power Co., Ltd. and Kagoshima University. By taking this opportunity, we would like to express our heartfelt thanks to Eko Co., Ltd. for their kind cooperation to the design and manufacture of measuring instruments. I would like to thank Mr. K. Yamashita, Mr. T.Kuroda and Mr. M.Sameshima, the students of Kagoshima University, for their valuable cooperation to the measurements.

\section{References}

1) E.A.SJERPS-KOOMEN, E.A.ALSEMA, W.C.TURKENBURG (1996) A SIMPLE MODEL FOR PV MODULE REFLECTION LOSSES UNDER FIELD CONDITIONS, Solar Energy, Vol. 57, No.6, pp.421-432

2) K.Otani, K.Sakuta, T.Sugiura and K.Kurokara (2001) PERFORMANCE ANALYSIS AND SIMULATION ON 100 JAPANESE RESIDENTIAL GRID-CONNECTED PV SYSTEM BASED ON FOUR YEAR EXPERIENCE, $17^{\text {th }}$ European Photovoltaic Solar Energy Conference and Exhibition, pp.22-26

3) R. Perez, P. Ineichen, R. Seals, J. Michalsky and R. Stewart (1990) Modeling Daylight Availability and Irradiance Components from Direct and Global Irradiance, Solar Energy, Vol.44, No.5, pp.271289 